\title{
Anxiogenic-Like Behavioral Phenotype of Mice Deficient in Phosphodiesterase 4B (PDE4B)
}

\author{
Han-Ting Zhang*,1,2, Ying Huang ${ }^{1,2}$, Anbrin Masood ${ }^{1,2}$, Lisa R Stolinski ${ }^{1,2}$, Yunfeng Li ${ }^{1,2}$, Lei Zhang ${ }^{3}$, \\ Daniel Dlaboga ${ }^{1,2}$, S-L Catherine Jin ${ }^{4}$, Marco Conti ${ }^{4}$ and James $M$ O'Donnell ${ }^{1,2}$
}

'Department of Behavioral Medicine and Psychiatry, West Virginia University Health Sciences Center, Morgantown, WV, USA; ${ }^{2}$ Department of Neurobiology and Anatomy, West Virginia University Health Sciences Center, Morgantown, WV, USA; ${ }^{3}$ Department of Psychiatry, Uniformed Services University of the Health Sciences, Bethesda, MD, USA; ${ }^{4}$ Division of Reproductive Biology, Department of Gynecology and Obstetrics, Stanford University School of Medicine, Stanford, CA, USA

\begin{abstract}
Phosphodiesterase-4 (PDE4), an enzyme that catalyzes the hydrolysis of cyclic AMP and plays a critical role in controlling its intracellular concentration, has been implicated in depression- and anxiety-like behaviors. However, the functions of the four PDE4 subfamilies (PDE4A, PDE4B, PDE4C, and PDE4D) remain largely unknown. In animal tests sensitive to anxiolytics, antidepressants, memory enhancers, or analgesics, we examined the behavioral phenotype of mice deficient in PDE4B (PDE4B-/-). Immunoblot analysis revealed loss of PDE4B expression in the cerebral cortex and amygdala of PDE4B-/- mice. The reduction of PDE4B expression was accompanied by decreases in PDE4 activity in the brain regions of PDE4B-/ - mice. Compared to PDE4B + / + littermates, PDE4B-/mice displayed anxiogenic-like behavior, as evidenced by decreased head-dips and time spent in head-dipping in the holeboard test, reduced transitions and time on the light side in the light-dark transition test, and decreased initial exploration and rears in the open-field test. Consistent with anxiogenic-like behavior, PDE4B-/- mice displayed increased levels of plasma corticosterone. In addition, these mice also showed a modest increase in the proliferation of neuronal cells in the hippocampal dentate gyrus. In the forced-swim test, PDE4B-/- mice exhibited decreased immobility; however, this was not supported by the results from the tail-suspension test. PDE4B-/mice did not display changes in memory, locomotor activity, or nociceptive responses. Taken together, these results suggest that the PDE4B subfamily is involved in signaling pathways that contribute to anxiogenic-like effects on behavior.

Neuropsychopharmacology (2008) 33, I6I I-1623; doi: I0.1038/sj.npp. I30 I537; published online I5 August 2007
\end{abstract}

Keywords: phosphodiesterase 4B (PDE4B); gene knockout; anxiogenic; antidepressant; neurogenesis; rolipram

\section{INTRODUCTION}

Phosphodiesterase-4 (PDE4), an enzyme that specifically catalyzes the hydrolysis of cyclic AMP (cAMP) and is critical in controlling its intracellular concentration, is involved in various central nervous system (CNS) processes, including depression (O'Donnell and Zhang, 2004), learning and memory (Barad et al, 1998), anxiety (Beer et al, 1972), and analgesia (Bradaia et al, 2005). Administration of PDE4 inhibitors such as rolipram produces antidepressant-like effects (Zhang et al, 2002, 2006), reverses memory deficits induced pharmacologically, physically, or genetically (Bourtchouladze et al, 2003; Imanishi et al, 1997; Zhang et al, 2000, 2004), alters anxiogenic-like behavior (Imaizumi et al, 1994; Silvestre et al, 1999a), and induces analgesia in rodents (Kumar et al, 2000). Inhibition of PDE4 also increases adult neurogenesis (Nakagawa et al, 2002), which is believed to be involved in antidepressant activity

*Correspondence: Dr H-T Zhang, Department of Behavioral Medicine and Psychiatry, West Virginia University Health Sciences Center, | Medical Center Dr., Morgantown, WV 26506, USA, Tel: + I 304 293 |488, Fax: + | 304293 | 634, E-mail: hzhang@hsc.wvu.edu Received 2 March 2007; revised I 4 July 2007; accepted I 6 July 2007
(Dranovsky and Hen, 2006; Malberg and Duman, 2003; Santarelli et al, 2003). However, the complexity of the PDE4 family, which includes four subfamilies (PDE4A, PDE4B, PDE4C, and PDE4D) and 21 splice variants (O'Donnell and Zhang, 2004), makes it unclear which subfamilies are involved in these actions.

PDE4 subfamilies may exert different functions based on their differential distributions in the brain (Cherry and Davis, 1999; Perez-Torres et al, 2000) and the compartmentation of cAMP signaling, which is controlled by different PDE4s (Baillie and Houslay, 2005; Fischmeister, 2006; Rich et al, 2007; Terrin et al, 2006). While the lack of selective inhibitors of PDE4 isoforms has made it particularly difficult in understanding the roles of PDE4 subfamilies, gene mutation and RNA interference (RNAi) have been shown to be feasible approaches to identifying functions of PDE4 subfamilies and even their variants (Lehnart et al, 2005; Lynch et al, 2005; Terrin et al, 2006; Zhang et al, 2002). Using genetic deletion mutants of specific PDE4 subtypes (Hansen et al, 2000; Jin et al, 2005b), it has been shown that PDE4D is important for antidepressant activity (Zhang et al, 2002). Mice deficient in PDE4D display antidepressant-like behavior in tests sensitive to antidepressants; the antidepressant-like effect of rolipram is 
abolished in these mice, which do not show any changes in a test sensitive to anxiolytic treatment. PDE4D may be involved in the mediation of memory, as indicated by memory-enhancing effects of PDE4 inhibitors exhibiting modest PDE4D selectivity (Zhang et al, 2005). More recently, PDE4D has been shown to be involved in the pathogenesis of stroke (Gretarsdottir et al, 2003; Zee et al, 2006). By contrast, very little is known regarding the role of PDE4B in CNS functions.

PDE4B has five splice variants (PDE4B1, 4B2, 4B3, 4B4, and 4B5; Bolger et al, 1993, 1994; Cheung et al, 2007; Huston et al, 1997; Shepherd et al, 2003). While the roles of these variants are still not known, recent studies using mice deficient in PDE4B have shown that this subfamily plays a complementary role in the control of neutrophil function (Ariga et al, 2004) and is required for antipsychotic effects of rolipram (Siuciak et al, 2007). In addition, PDE4B also is involved in schizophrenia by interacting with the DISC1 gene, a candidate susceptibility factor for schizophrenia (Clapcote et al, 2007; Millar et al, 2005). These results indicate that PDE4B plays a significant role in CNS functions.

Studies to date indicate that PDE4B may be involved in the regulation of anxiety and depression. First, PDE4B is the predominant PDE4 subtype in the amygdala, hypothalamus, and striatum; it also is expressed at relatively high levels in the frontal cortex and olfactory bulb (Cherry and Davis, 1999; Perez-Torres et al, 2000). The amygdala and hypothalamus are key regions in the mediation of anxiety and stress responses (Charney and Deutch, 1996), while the frontal cortex and olfactory bulb contribute in the mediation of antidepressant effects on behavior (Soares and Mann, 1997; Webster et al, 2000). Second, the benzodiazepine anxiolytic diazepam inhibits PDE4 expressed in HEK293 cells in vitro; PDE4B is more sensitive to inhibition by diazepam than PDE4A (Cherry et al, 2001). Third, chronic nicotine treatment, which appears to induce anxiolytic- and antidepressant-like effects (Biala and Budzynska, 2006; Semba et al, 1998), produces downregulation of PDE4B in the brain (Polesskaya et al, 2007). Finally, chronic treatment with antidepressants decreases the expression of PDE4B in the mouse hippocampus (Dlaboga et al, 2006) and increases adult neurogenesis (Malberg et al, 2000). However, since there are no highly selective inhibitors of individual PDE4 subtypes, direct evidence for the potential involvement of PDE4B in anxietyand depression-like behaviors is lacking. Hence, we examined behaviors of mice deficient in PDE4B using a battery of animal tests sensitive to anxiolytics, antidepressants, memory enhancers, and analgesics. In addition, we compared the expression of PDE4 subtypes and PDE activity in the brain, neuronal cell proliferation in the hippocampus, and plasma corticosterone levels between PDE4B-I- mice and their wild-type controls.

\section{MATERIALS AND METHODS}

\section{Animals}

Adult male mice with the same mixed genetic background $(\mathrm{C} 57 \mathrm{BL} / 6 \times 129 / \mathrm{Ola})$ were used in experiments involving PDE4B-/- mice, which were generated by homologous recombination as described previously (Jin et al, 1999). Wildtype $(\mathrm{PDE} 4 \mathrm{~B}+/+)$ and $\mathrm{PDE} 4 \mathrm{~B}-/-$ offspring used in the experiments were derived from mating of heterozygous (PDE4B $+/-)$ mice. Genotype was determined by Southern blot analysis of genomic DNA. All mice were housed in groups of 1-4 per cage in a temperature-controlled room $\left(22-23^{\circ} \mathrm{C}\right)$ with a $12-\mathrm{h}$ on/12-h off light cycle (lights on at 0600 hours). Water and food were freely available in their home cages. Blind observations were used throughout all the experiments, which were performed from 0900 to 1300 hours in a quiet room. All procedures were approved by the Animal Care and Use Committee of West Virginia University Health Sciences Center, and were performed according to the 'NIH Guide for the Care and Use of Laboratory Animals' (NIH Publications No. 80-23, revised 1996).

\section{Immunoblotting of PDE4 Subtypes in the Mouse Brain}

The experiment was performed as described previously (Dlaboga et al, 2006; Richter et al, 2005). In brief, PDE4B + / + and $\mathrm{PDE} 4 \mathrm{~B}-/-$ mice were decapitated and brain regions (cerebral cortex, amygdala, and hippocampus) were dissected and kept frozen $\left(-80^{\circ} \mathrm{C}\right)$ until testing. Brain tissues were homogenized in RIPA buffer ( $50 \mathrm{mM}$ Tris, $\mathrm{pH} 8.0$, $150 \mathrm{mM} \mathrm{NaCl}, 1 \%$ Nonidet P-40, 0.5\% sodium deoxycholate, and $0.1 \%$ SDS) and centrifuged at $16000 \mathrm{~g}$ for $20 \mathrm{~min}$. One half of the supernatant was immunoprecipitated with specific polyclonal PDE4A, PDE4B, or PDE4D antibodies (FabGennix Inc., Frisco, TX), which were generated against the unique C-terminal of each isoform and detected all known variants within any particular PDE4 subfamily without crossreaction (Dlaboga et al, 2006). The immunoprecipitated $\mathrm{PDE} 4 \mathrm{~A}, \mathrm{PDE} 4 \mathrm{~B}$, and $\mathrm{PDE} 4 \mathrm{D}$ proteins were separated by SDS-PAGE, transferred to nitrocellulose, and detected by immunoblotting using the respective PDE4 subtype-specific antibodies.

\section{PDE Assay}

The other half of the above supernatants from the cerebral cortex, amygdala, and hippocampus were used for PDE assay, as described previously (Zhang et al, 2002). PDE activity was determined by the detection of the $\left[{ }^{3} \mathrm{H}\right]$ cAMP converting rate, using unlabeled cAMP $(1 \mu \mathrm{M})$ as the substrate, in the absence (total PDE activity) and presence (non-PDE4 activity) of $10 \mu \mathrm{M}$ rolipram; PDE4 activity was determined by subtracting non-PDE4 activity from the total PDE activity.

\section{Cell Proliferation by Immunohistochemistry}

This was performed as described previously (Nakagawa et al, 2002). In brief, groups of PDE4B + / + and PDE4B-Imice were injected (i.p.) with $50 \mathrm{mg} / \mathrm{kg}$ BrdU (Sigma, St Louis, MO) three times at $1 \mathrm{~h}$ intervals. Thirty minutes after the last injection, mice were killed via intracardial perfusion, the brains were post-fixed, and serial coronal sections $(30 \mu \mathrm{m})$ through the entire hippocampus were collected using a freezing microtome. Every 9th section was slide-mounted for peroxidase BrdU/Tuj1 (neuronal-specific protein for immature neurons) immunolabeling. The sections were incubated with mouse monoclonal antibody 
against BrdU (1:1000; Sigma) and murine anti-Tuj1 antibody (1:500; Babco, Richmond, CA) followed by goat antimouse secondary antibody labeled with Alexa 488 (green fluorescence for BrdU) or Alexa 568 (red fluorescence for Tuj1). The sections were analyzed by confocal laser microscopy.

For immunofluorescence staining, free-floating sections were incubated with the primary antibody (mouse antiBrdU monoclonal IgG; $1: 1000)$ and then FITC-conjugated goat anti-mouse IgG $(1: 200$, Jackson ImmunoResearch, West Grove, PA) following the procedures reported previously (Nakagawa et al, 2002). The number of BrdUpositive cells in bilateral, entire hippocampi was counted through a $\times 40$ objective (Zeiss, Oberkochen, Germany). Ten sections were analyzed to cover the entire hippocampus. The total number of BrdU-positive cells in both sides of the granule cell layer was multiplied by 9 and reported as the total number of cells.

\section{Determination of Plasma Corticosterone Concentrations}

One week after the holeboard test (Figure 1c), mice were anesthetized with ketamine $(100 \mathrm{mg} / \mathrm{kg})$ and xylazine (10 mg/kg) before blood collection. Blood was harvested by exsanguinations using heparinized syringes and collected in Eppendorf tubes. Plasma corticosterone concentrations were quantified by ELISA following the manufacturer's instructions (OCTEIA Corticosterone EIA, IDS, Boldon, UK).

\section{Behavioral Test Procedures}

Three batches of PDE4B + / + and PDE4B $-/-$ mice, $15-$ to 18-week-olds at the beginning of tests and 25- to 28-week(Figure 1a), 24- to 27-week- (Figure 1b), or 18- to 21-weekolds (Figure 1c) by the end of tests, were used for batteries of behavioral tests. More than one batch of mice was used to limit the repetition of tests using the same animals. In addition, to reduce potential influence of stress and/or the previous test, all mice were handled for 1 week before the beginning of tests and given 1-2 weeks break between the tests; tests involving less stress (eg open-field and water-maze tests) were performed before those that were more stressful (eg hot-plate and writhing tests). In the drug treatment group, mice were tested with saline 1 week before drug tests to monitor the baseline of immobility in the FST (Figure 1b); the lower dose of desipramine and acute rolipram were tested 1 week before the higher dose of desipramine and chronic rolipram, respectively.

\section{Anxiogenic-Like Effects on Behavior}

The open-field exploration test. This test utilizes behavioral changes in rodents exposed to a novel environment and has been used to evaluate anxiogenic and anxiolytic activity under identical situations (Pellow, 1986). The test used was modified slightly from the previous procedure (Moreira et al, 2000). The floor of the open-field chamber $(50 \times 50 \times 25 \mathrm{~cm})$, which was made of white Plexiglas, was divided into 16 identical squares. The naive mouse was placed at one corner of the chamber and allowed to explore for $5 \mathrm{~min}$. The latency (ie the time taken to move from the corner square to the next adjacent square), exploration (ie the number of squares crossed), and rears (ie the number of times the animals stood on its rear paws) were recorded.

The holeboard test. This was performed as described previously (Hilakivi and Lister, 1990). The holeboard apparatus consisted of an open Plexiglas box $(40 \times 40 \times 30 \mathrm{~cm})$ with four holes $(3 \mathrm{~cm}$ in diameter, $2 \mathrm{~cm}$ in depth) in the black floor. The test was performed in a dimly lit room. Mice were placed individually in the center of the floor and allowed to explore for $5 \mathrm{~min}$. The number of head-dips and the time spent in head-dipping were recorded.

The light-dark transition test. The test was performed as described previously (MacNeil et al, 1997). Mice were individually placed in the dark compartment $(15 \times 23 \mathrm{~cm})$ of the light-dark chamber. The latency to cross through the hole $(8 \times 6 \mathrm{~cm})$ into the light compartment $(30 \times 23 \mathrm{~cm}$; illuminated with a $60-\mathrm{W}$ bulb positioned $50 \mathrm{~cm}$ above), the time spent in the light compartment, and transitions, defined as the number of crossings from the dark compartment to the light side, were recorded for $5 \mathrm{~min}$.

\begin{tabular}{|l|l|l|l|l|}
\hline Habituation & Open-field & Water-maze & Tail-flick & Light-dark transition \\
\hline
\end{tabular}

\begin{tabular}{|l|l|l|}
\hline Step-down & Hot-plate & Writhing \\
\hline
\end{tabular}

\begin{tabular}{|l|c|l|l|l|l|}
\hline Habituation & TST & FST: Session 1 & FST: Sal, Des & FST: Sal, Rol & FST: Session 2 \\
\hline
\end{tabular}

\begin{tabular}{|l|l|l|l|}
\hline Habituation & Open-field exploration & Holeboard & Plasma corticosterone \\
\hline
\end{tabular}

Figure I The schedule of behavioral tests for three groups ( $a, b$, and $c)$ of PDE4B $+/+$ and PDE4B $-/-$ mice. Six to eight mice per genotype in each group were used in the batteries of behavioral tests and in the examination of plasma corticosterone (c). All animals were habituated for I week before tests. Intervals between tests were I-2 weeks. TST, the tail-suspension test; FST, the forced-swim test; Des, desipramine; Sal, saline; Rol, rolipram (acute and repeated administration). 


\section{Antidepressant-Like Effects on Behavior}

Tail-suspension test (TST). The TST was performed as described previously (Zhang et al, 2002). Each mouse was suspended using adhesive tape placed approximately $1 \mathrm{~cm}$ from the tip of its tail. The duration of immobility (ie passive hanging and complete motionlessness) was recorded during the 6 min test period.

The forced-swim test (FST). This was performed as described previously (Zhang et al, 2002). Mice were individually placed in a plastic cylinder $(45 \mathrm{~cm}$ high $\times 20 \mathrm{~cm}$ diameter) filled with water $\left(22-23^{\circ} \mathrm{C} ; 28 \mathrm{~cm}\right.$ in depth), allowing for free swimming. The duration of immobility, which was defined as floating in an upright position without additional moving other than that necessary for the animal to keep its head above water, was recorded for $6 \mathrm{~min}$. The test was repeated 7 weeks later to confirm the behavioral observations.

\section{Measurement of Memory Performance}

Step-down passive avoidance task. The experiment was performed as described previously (Maurice and Privat, 1997), with minor modifications. During the training, each mouse was placed on a wooden platform $(3.5 \times 3.5 \times 2.5 \mathrm{~cm})$ that was fixed at the center of the grid floor (connected to an isolated pulse stimulator; Model E1308, Coulbourn, Allentown, PA) of a Plexiglas chamber $(25 \times 15 \times 10 \mathrm{~cm})$. The mouse was subjected to a footshock $(0.4 \mathrm{~mA}, 5 \mathrm{~s})$ as soon as it completely descended to the grid floor. This procedure was repeated immediately and again $1 \mathrm{~h}$ after the initial training. Retention tests (no shocks) were performed for 3 and $24 \mathrm{~h}$ and then, for assessing the extinction of memory, 8 days after the last training, with an upper cut-off time of $300 \mathrm{~s}$.

Morris water-maze task. Spatial learning and memory were assessed using the Morris water-maze task as described previously (El-Ghundi et al, 1999), with minor modifications. In brief, during the acquisition training, mice were trained ( 6 trials $\times 2$ days plus 4 trials $\times 1$ day) in a pool $\left(65 \mathrm{~cm}\right.$ high $\times 59 \mathrm{~cm}$ diameter) filled with water $\left(22 \pm 1^{\circ} \mathrm{C}\right.$, $15 \mathrm{~cm}$ in depth) to escape by swimming to the platform $(12 \mathrm{~cm}$ high $\times 7.5 \mathrm{~cm}$ diameter) hidden $1 \mathrm{~cm}$ under the water in one of four quadrants. The escape latency (ie the time required to locate and climb onto the platform) for each mouse was recorded. Twenty-four hours after the last trial, the probe trial was started. The platform was removed, and the number of entries into and time spent in the target quadrant (the previous location of the platform) were recorded during the $60 \mathrm{~s}$ test.

\section{Measurement of Nociceptive Responses}

The hot-plate test. This was performed as described previously (Ballou et al, 2000). Mice were individually placed at the center of the heated flat surface $(25 \times 25 \mathrm{~cm}$; $55^{\circ} \mathrm{C}$ ) of an Analgesia Meter (Columbus Instrument, Columbus, $\mathrm{OH}$ ) and removed immediately after they licked the footpad of the hind paw. The latency (ie the time spent before paw licking) was recorded with a cut-off time of $30 \mathrm{~s}$.
The tail-flick test. This was performed as described previously (Bohn et al, 2000). Latency to respond to warm water $\left(50^{\circ} \mathrm{C}\right)$ was measured to assess the nociceptive response; this was defined as the removal of the tail from the warm water.

The writhing test. Mice were injected (i.p.) with $1 \%$ acetic acid $(10 \mathrm{ml} / \mathrm{kg})$ and placed separately in transparent, plastic cages $(25 \times 50 \times 25 \mathrm{~cm})$. Five minutes later, a 5 -min observation was initiated, during which the number of writhes (defined as constriction of the abdomen with stretching of the hind legs) was recorded.

\section{Measurement of Locomotor Activity}

This was performed using the open-field chamber. The floor was divided into four identical squares. Naive mice were individually placed in the center of the chamber and allowed to explore for $30 \mathrm{~min}$, during which the number of line crossings (with all four paws crossed the line) and rears (ie the number of times the animals stood on its rear paws) were recorded every $5 \mathrm{~min}$.

\section{Statistical Analyses}

All data were analyzed using Student's $t$-tests except for those in the forced-swim, step-down, and water-maze tests, in which two-way ANOVA was used followed by NewmanKeuls comparison tests.

\section{RESULTS}

\section{Loss of PDE4B Expression and Reduction of PDE4 Activity in PDE4B-I- Mice}

To confirm the deficiency of PDE4B in the brains of PDE4B-I- mice, western blotting was used to analyze the expression of the PDE4 subtypes in the cerebral cortex, amygdala, neostriatum, hippocampus, and cerebellum from $\mathrm{PDE} 4 \mathrm{~B}+/+, \mathrm{PDE} 4 \mathrm{~B}+/-$ (heterozygous knockout), and PDE4B-I- mice. The results revealed that the PDE4B1/3 isoforms were not expressed in the cerebral cortex of PDE4B-I- mice; by contrast, the expression of PDE4A (4A5) and PDE4D (4D3) was not changed (Figure 2a). $\mathrm{PDE} 4 \mathrm{~B}+/-$ mice exhibited intermediate expression of $\mathrm{PDE} 4 \mathrm{~B}$ relative to the $\mathrm{PDE} 4 \mathrm{~B}+/+$ and $\mathrm{PDE} 4 \mathrm{~B}-/-$ mice. Similar patterns of expression also were observed in the other regions of the brain (data not shown). Thus, PDE4B was selectively knocked out in PDE4B-/- mice. Activities of PDE4, non-PDE4, and total PDEs were determined in the brain regions. Consistent with the reduced PDE4B expression, PDE4 activity (ie rolipram-sensitive PDE activity) was decreased in the brains of PDE4B-I- mice; it was reduced by $33 \%$ in the cerebral cortex $(P<0.001$; Figure $2 \mathrm{~b})$ and $68 \%$ in the amygdala $(P=0.002$; Figure $2 \mathrm{c})$. In contrast, nonPDE4 activity was not significantly different from that in the PDE4B $+/+$ mice. Total PDE activity was decreased in the amygdala $(P<0.01)$ and tended to be decreased in the cerebral cortex $(P=0.06)$ in PDE4B $-I-$ mice. Similar decreases in PDE4 activity also were observed in the other regions tested except for the hippocampus, in which PDE4 
a

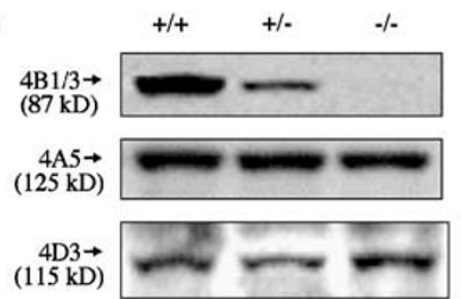

b

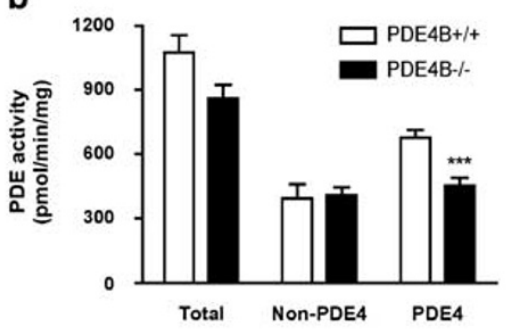

d

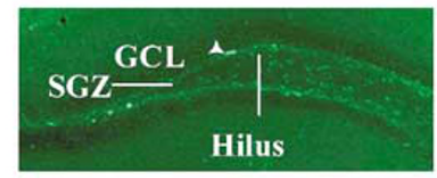

f
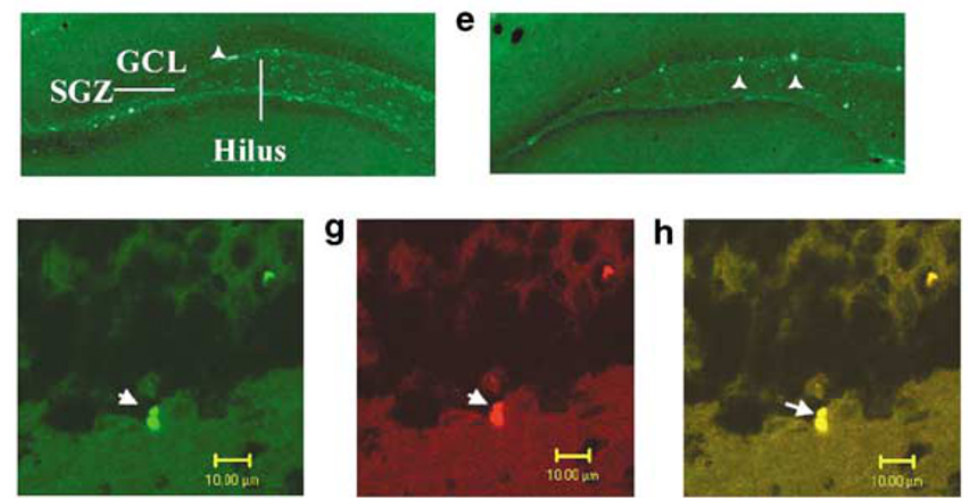
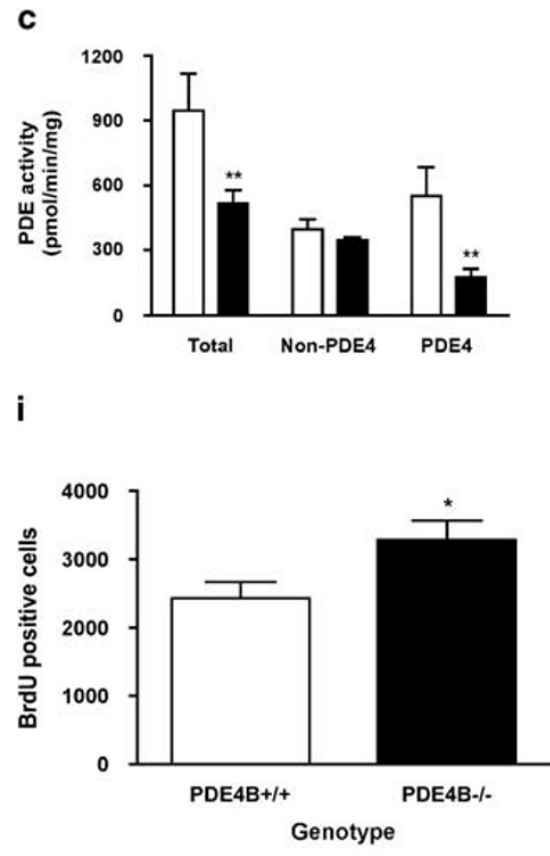

Figure 2 PDE4B-/- mice displayed decreases in PDE4B expression and PDE4 activity and an increase in neurogenesis. (a) Mice deficient in PDE4B (-/-) displayed a decrease in the expression of PDE4BI/3, but did not show any changes in that of PDE4A (A5) and PDE4D (D3) in cerebral cortices, relative to PDE4B wild-type $(+/+)$ controls. PDE4B heterozygous $(+/-)$ mice displayed intermediate expression in PDE4BI/3 relative to PDE4B + / + and PDE4B-/ - mice. The tissues were homogenized and immunoprecipitated as described in the Methods section. The proteins of PDE4BI/3, PDE4A5, and PDE4D3 were detected by western blot analysis. Molecular weights of the PDE4 variants are shown in parentheses (Dlaboga et al, 2006). (b and c) PDE4B-/- mice displayed decreased PDE4 activity, but no change in non-PDE4 activity in both the cerebral cortex (b) and the amygdala (c). In contrast, these mice exhibited decreases in total PDE activity in the amygdala and a tendency toward decreased total PDE activity in the cerebral cortex. PDE4 activity was obtained by subtracting non-PDE4 (ie rolipram-sensitive PDE) activity from total PDE activity. (d and e) Representative photomicrographs of the hippocampal dentate gyrus from PDE4B + I+ (d) and PDE4B-I- (e) immunofluorescent staining for BrdU-positive cells (arrowhead), which were predominantly localized in the subgranular zone (SGZ) and within the granule cell layer (GCL). (f-h) Representative photomicrographs of cells double immunostaining (h; yellow) for Tujl (f; green) and BrdU (g; red) in the GCL of the dentate gyrus of the hippocampus from PDE4B-/- mice. (i) Quantification of BrdU and Tuj I double-positive cells. PDE4B-/ - mice displayed an increase in cell proliferation. Data shown represent the mean \pm SEM of $7-8$ mice per group. $* P<0.05$; $* * P<0.0$; **** $P<0.00$ I vs PDE4B $+1+$ (two-tailed Student's $t$-test).

activity tended toward a decrease (ie by $22 \%$ ) but this was not significant (data not shown).

\section{PDE4B-I- Mice Displayed Increases in Hippocampal Neurogenesis}

To determine changes in neurogenesis, the number of newborn cells, an index of proliferation (Duman et al, 2001), in the dentate gyrus of the hippocampus was examined by immunohistochemical detection of bromodeoxyuridine (BrdU) within nuclei of dividing cells. The immature neuron marker Tuj1 was used to label newly born cells. BrdU-positive nuclei of proliferating cells were localized predominantly in the subgranular layer, ie the border between granule cell layer (GCL) and hilus, and within GCL in both PDE4B $+/+$ and PDE4B $-/-$ mice (Figure 2d and e). Cells double-labeled for Tuj1 and BrdU in the GCL appeared in clusters of two or more (Figure 2f-h), indicating incorporation of BrdU occurs during proliferation of granule cells. BrdU-positive cells were slightly, but significantly increased in the GCL of hippocampal dentate gyrus from $\mathrm{PDE} 4 \mathrm{~B}-1-$ mice relative to those from PDE4B $+/+$ controls $(P<0.05$; Figure $2 \mathrm{i})$.

\section{Anxiogenic-Like Behavior of PDE4B-I- Mice}

To determine the role of PDE4B in the regulation of anxiety, we examined behaviors of PDE4B-I- mice and their wildtype controls in a battery of anxiety tests, including the holeboard, light-dark transition, and open-field exploration tests. In the holeboard test, PDE4B-I- mice displayed significant decreases in the number of head-dips $(P<0.001)$ and the time spent in head-dipping relative to $\mathrm{PDE} 4 \mathrm{~B}+I+$ controls $(P<0.01$; Figure 3a), indicating an anxiogenic-like effect. Consistent with this, in the light-dark transition test, PDE4B-I- mice exhibited an increase in the latency to cross from the dark to the light compartment $(P<0.05$; Figure $3 \mathrm{~b})$ and decreases in the number of transitions $(P<0.05$; Figure $3 \mathrm{c})$ and duration, ie the time spent in the light compartment, compared to the PDE4B $+/+$ mice $(P<0.05$; Figure $3 \mathrm{~d})$. Similarly, in the open-field test, PDE4B-I- mice showed decreases in exploration, ie an increase in the latency to exit the initial quadrant $(P<0.05$; Figure $4 \mathrm{a})$ and decreases in initial exploration $(P<0.01$; Figure $4 \mathrm{~b})$ and rears $(P<0.001$; Figure $4 \mathrm{c})$. These data suggest that mice deficient in PDE4B display anxiogeniclike behavior. These effects appeared not to be associated with changes in general activity since PDE4B- $/-$ mice did not show altered locomotor activity (see below). 

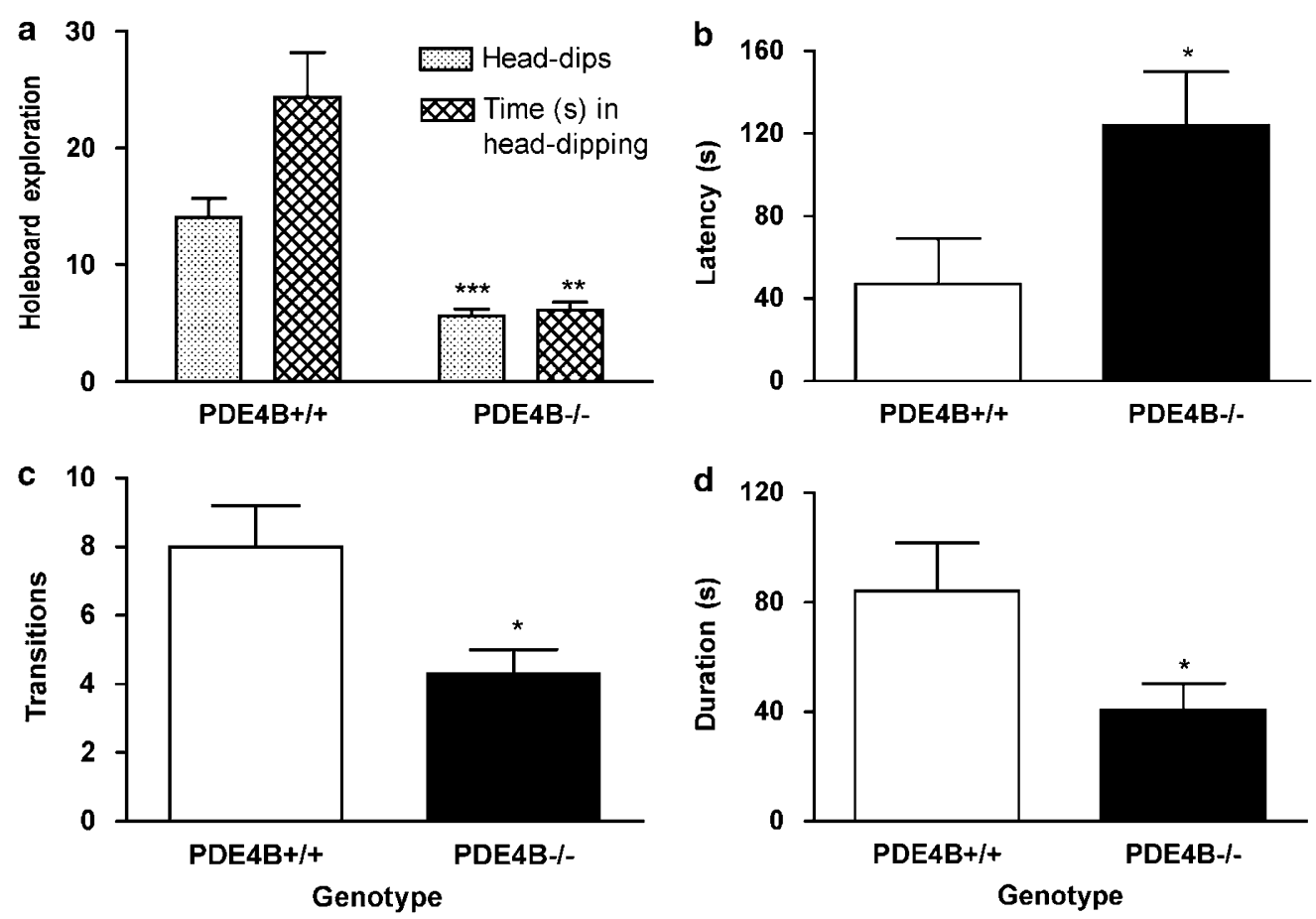

Figure 3 PDE4B-/- mice displayed anxiogenic-like effects on behavior in the holeboard and light-dark transition tests. (a) PDE4B-/- mice displayed decreases in head-dips and time spent in head-dipping in the holeboard test. (b-d) PDE4B-/- mice displayed decreases in latency (b) before crossing over to the light compartment, transitions (c) from the dark compartment to the light side, and duration (d), ie the time spent in the light compartment. Data shown represent the mean \pm SEM of $7-10$ mice per group; $* P<0.05$; $* * P<0.0$ I; **** $P<0.001$ vs PDE4B $+1+$ (two-tailed Student's $t$-test).

Consistent with the behavioral observations, PDE4B-/mice displayed a significant increase in plasma corticosterone levels relative to $\mathrm{PDE} 4 \mathrm{~B}+/+$ controls $(P<0.001$; Figure $4 \mathrm{~d}$ ), suggesting a greater susceptibility of mice deficient in PDE4B to stress.

\section{PDE4B-I- Mice Displayed Antidepressant-Like Behavior}

To determine the potential role of PDE4B in antidepressantlike activity, PDE4B-I- mice and their wild-type controls were first tested in the TST followed by the FST with or without treatment with rolipram or desipramine. In the TST, PDE4B-I- mice tended to show an increase in immobility compared to the wild-type control $(P=0.11$; Figure 5a). By contrast, in the FST, PDE4B $-/-$ mice displayed decreases in the duration of immobility relative to PDE4B $+/+$ littermates $(P<0.05$; Figure $5 \mathrm{~b}$, Session 1$)$; this was verified in a second test performed 7 weeks later using the same mice $(P<0.01$; Figure $5 \mathrm{~b}$, Session 2$)$. While acute treatment with rolipram did not alter forced-swim behavior in either genotype, repeated treatment with rolipram $(0.5 \mathrm{mg} / \mathrm{kg}$, i.p. for 8 days $)$ decreased immobility in the PDE4B $+/+$, but not PDE4B $-/-$ mice $(P<0.05$; Figure $5 \mathrm{c})$. Similarly, acute administration of desipramine at doses of 20 and $40 \mathrm{mg} / \mathrm{kg}$ reduced immobility only in PDE4B + / + mice $(P<0.01$ and $P<0.001$, respectively; Figure $5 \mathrm{~d})$.

\section{Memory Performance of PDE4B-I- Mice}

To determine whether PDE4B deficiency altered memory, we examined the performance of $\mathrm{PDE} 4 \mathrm{~B}-/-$ mice and their wild-type controls in step-down passive avoidance and Morris water-maze tasks. In the step-down test, compared to $\mathrm{PDE} 4 \mathrm{~B}+/+$ controls, PDE4B $-/-$ mice did not display any changes in either short-term $(3 \mathrm{~h})$ or long-term ( 1 and 8 days) retention (Table 1). Similarly, in the water-maze test, while both PDE4B $+/+$ and PDE4B $-/-$ mice displayed progressive decreases in escape latency during the acquisition training, there was no difference between the genotypes (Figure 6a). In addition, PDE4B- - - mice did not show any different changes in entries into and time spent in the target quadrant in the probe trial (Figure 6b). Negative results also were obtained in the radial-arm maze test (data not shown).

\section{Nociceptive Responses of PDE4B-I- Mice}

To determine the potential role of PDE4B in nociception, we examined the responses of PDE4B-I- mice and their wild-type littermates in three nociceptive tests: the hotplate, tail-flick, and acetic acid-induced writhing tests. Compared to PDE4B $+/+$ controls, PDE4B $-/-$ mice did not exhibit altered nociceptive responses, as evidenced by unchanged latencies of paw licking and tail-flick and number of writhes in the three tests, respectively (Table 2).

\section{Locomotor Activity in PDE4B-I- Mice}

In the open-field test, PDE4B-/- mice displayed a decrease in line crossings in the first 5 min relative to the $\mathrm{PDE} 4 \mathrm{~B}+/+$ controls $(P<0.05)$. However, this was not repeated at the other time points (Figure $7 \mathrm{a}$ ); the total line crossings in the $30 \mathrm{~min}$ test period were not altered either (Figure $7 \mathrm{c}$ ). $\mathrm{PDE} 4 \mathrm{~B}-/-$ mice tended to show decreases in rears over the 

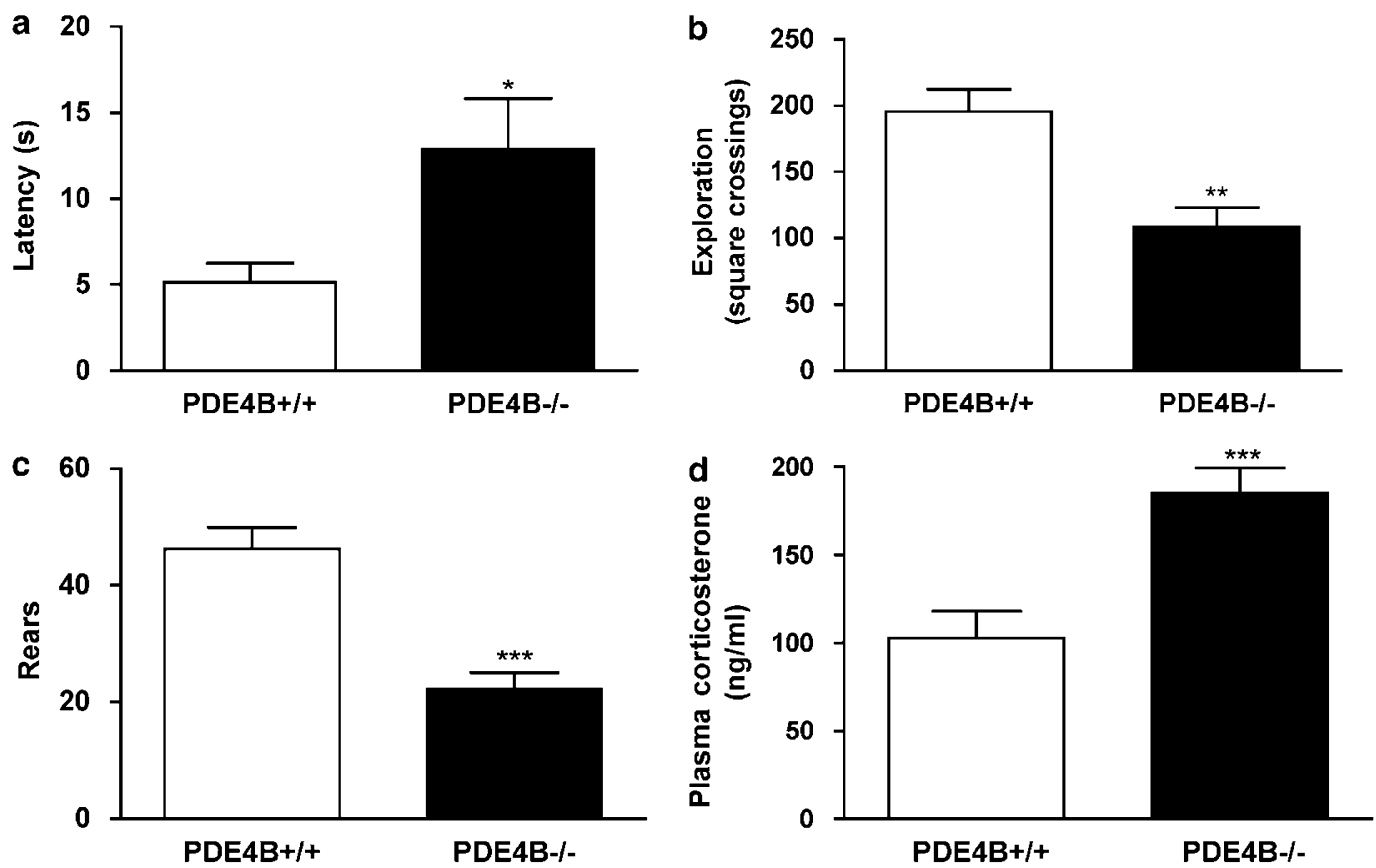

Figure 4 PDE4B-/- mice displayed anxiogenic-like effects on open-field behavior and increases in plasma corticosterone levels. (a-c) PDE4B-/- mice showed increased latency to explore, decreases in initial exploration (b), ie the number of squares crossed, and rears (c) in the novel open-field test. (d) PDE4B-1- mice displayed increases in plasma corticosterone levels. Data shown represent the mean \pm SEM of $7-10$ mice per group. * $P<0.05$; ** $P<0.0$ I; **** $P<0.00$ I vs PDE4B + I + (two-tailed Student's t-test).
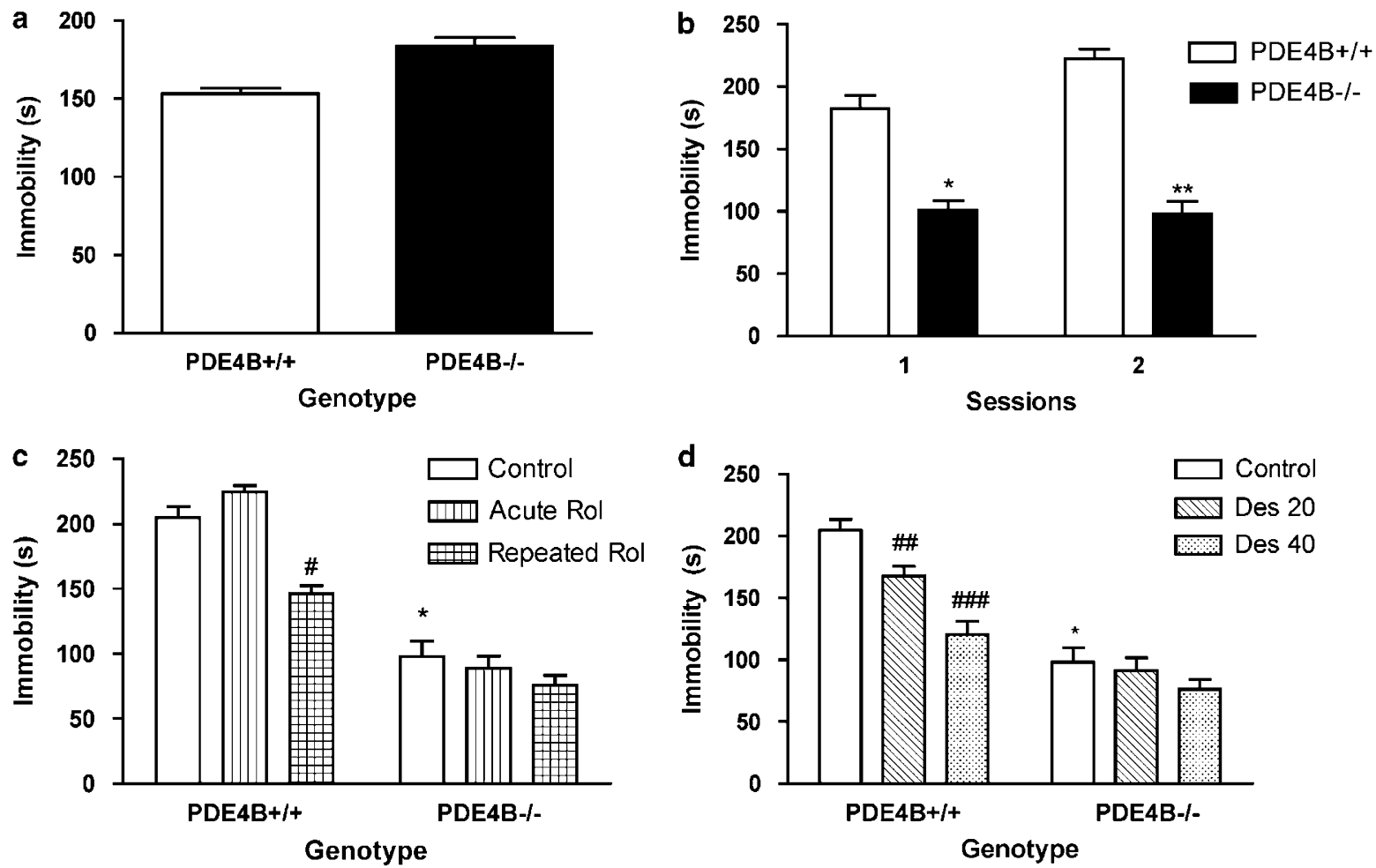

Figure 5 Behaviors of PDE4B-/ - mice in the TST (a) and FST (b-c). (a) PDE4B-/- mice did not show significant changes in immobility in the TST; (b) PDE4B-/ - mice displayed decreases in immobility duration in Session I and 2 of FST (there was a 7 weeks interval between the sessions). (c) Repeated treatment with rolipram (Rol) decreased immobility in PDE4B + / , but not PDE4B-/ - mice. Rol $(0.5 \mathrm{mg} / \mathrm{kg}$, i.p.) was given singly (Acute Rol) or once a day for 8 days (Repeated Rol). (d) Desipramine (Des) decreased immobility in PDE4B $+/+$, but not PDE4B-/- mice. Mice were tested 30 min after the single Rol or Des or the last Rol injection. Data shown represent the mean \pm SEM of $7-8$ mice per group. *P $<0.05$; $* * P<0.0$ I vs corresponding PDE4B $+/+$ mice and ${ }^{\#} P<0.05 ;{ }^{\#} P<0.01 ;{ }^{\# \#} P<0.001$ vs control in the same genotype (two-tailed Student's t-test). 
test times (Figure 7b) and displayed a significant decrease in the total rears compared to the wild types $(P<0.05$; Figure $7 d)$. These results were consistent with the decreased open-field exploration and anxiogenic behavior described above. In addition, the overall unaltered line crossings suggest unchanged locomotor activity in PDE4B-/- mice.

\section{DISCUSSION}

It is well established that PDE4 inhibitors such as rolipram produce antidepressant-like and memory-enhancing effects

Table I Retention Latency of PDE4B $+/+$ and PDE4B-/- at the Time Points of $3 \mathrm{~h}, \mathrm{I}$ day, and 8 days after Initial Training in the Step-Down Passive Avoidance Test

\begin{tabular}{lccc}
\hline & \multicolumn{3}{c}{ Latency (s) } \\
\cline { 2 - 4 } & $\mathbf{3 h}$ & $\mathbf{I}$ day & $\mathbf{8}$ day \\
\hline PDE4B+/+ & $163.7 \pm 46.9$ & $218.2 \pm 44.3$ & $192.8 \pm 41.4$ \\
PDE4B-/- & $189.1 \pm 40.5$ & $223.0 \pm 38.9$ & $203.1 \pm 47.3$
\end{tabular}

Data shown represent the mean \pm SEM of 6-7 mice per group. The latency was the time before the animal descended to the grid floor where they had previously received a mild, inescapable footshock. Compared to PDE4B $+/+$ controls, PDE4B-/ - mice did not display any changes in either short-term $(3 \mathrm{~h})$ or long-term ( $\mathrm{I}$ and 8 days) retention, as revealed by two-way ANOVA and unpaired $t$-tests.
(Barad et al, 1998; O'Donnell and Zhang, 2004; Zhang et al, 2004, 2006; Zhang and O'Donnell, 2007). They also may induce anxiogenic-like effects and sedation (Heaslip and Evans, 1995; Imaizumi et al, 1994; Silvestre et al, 1999b), although an anxiolytic-like effect also has been reported (Silvestre et al, 1999a). While studies have shown that PDE4D plays an important role in the mediation of antidepressant-like effect (Zhang et al, 2002) and may be involved in memory (Zhang et al, 2004, 2005), the role of PDE4B has not been investigated due to the lack of highly selective inhibitors of individual PDE4 subtypes and the complexity of the PDE4 family in terms of its numerous variants and compartmentation (Conti et al, 2003; Houslay et al, 2005; Terrin et al, 2006). Using mice deficient in $\mathrm{PDE} 4 \mathrm{~B}$, it has been demonstrated that this subtype plays a critical role in lipopolysaccharide-induced signaling and inflammatory responses (Ariga et al, 2004; Jin et al, 2005a). Most recently, it has been shown that PDE4B is required for the antipsychotic effect of rolipram (Siuciak et al, 2007), which is consistent with the association of this subtype with schizophrenia (Millar et al, 2005). Nevertheless, little is known about the CNS function of PDE4B. In the present study, it was found that PDE4B was involved in behaviors associated with anxiety, but not memory and nociception.

While it is relatively well established that PDE4 is involved in antidepressant-like and memory-enhancing effects, the regulation of anxiety by PDE4 remains largely unknown. The reports to date are inconsistent. One study showed that the PDE4 inhibitor rolipram produced an anxiolytic-like effect in rats (Silvestre et al, 1999a), whereas
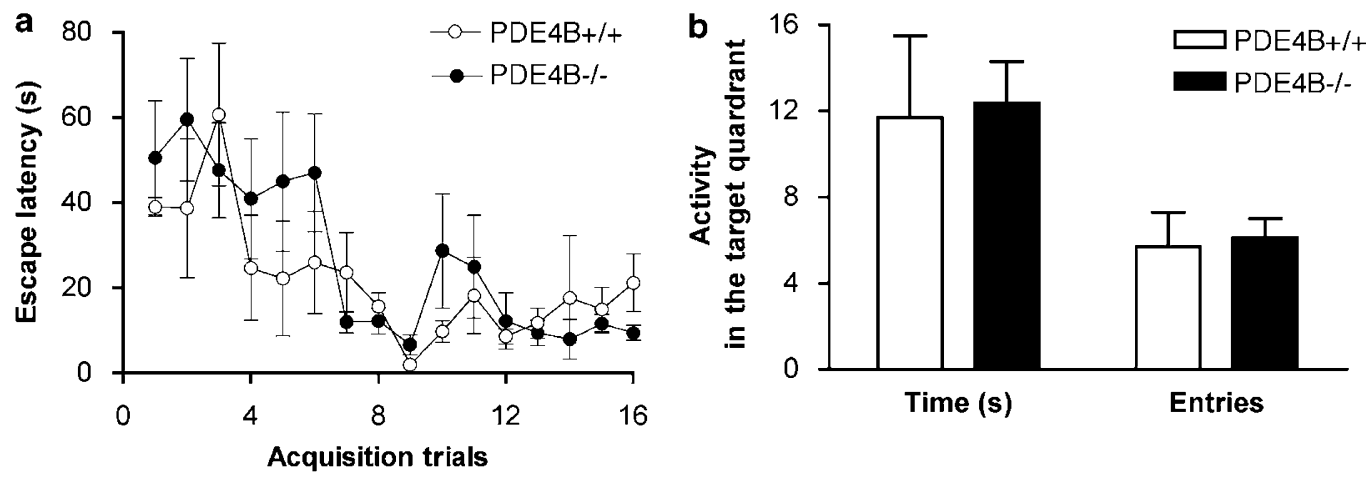

Figure 6 PDE4B-/- mice did not exhibit altered performance in the Morris water-maze task. (a) PDE4B-/- mice did not show significant changes in escape latencies in the acquisition training trials relative to PDE4B + / controls. (b) PDE4B-/ - mice did not display any changes in either entries into or time spent in the target quadrant in Probe Trial I given $24 \mathrm{~h}$ after the last acquisition trial. All the observations were performed for $60 \mathrm{~s}$. Data shown represent mean \pm SEM of 6-7 mice per group. There was no difference between the genotypes as revealed by two-way ANOVA (for a) or unpaired $t$-tests (b).

Table 2 Comparison of Nociceptive Responses Between PDE4B+/+ and PDE4B-/- Mice in the Hot-Plate, Tail-Flick, and Acetic AcidInduced Writhing Tests

Hindpaw licking latency (s)

Tail-flick latency $(\mathbf{s})$

Number of writhes

\begin{tabular}{llll}
\hline PDE4B+/+ & $19.3 \pm 1.3$ & $3.0 \pm 0.1$ & $6.5 \pm 2.0$ \\
PDE4B-/- & $20.6 \pm 3.2$ & $3.4 \pm 0.4$ & $8.6 \pm 1.4$ \\
\hline
\end{tabular}

Data shown represent the mean + SEM of 7-8 mice per group. The latency was the time before the animal licked its hind paw in the hot-plate test or removed its tail from the water in the tail-flick test with a cut-off time of $30 \mathrm{~s}$. The number of writhes, which was defined as constriction of the abdomen with stretching of the hind legs, was recorded for 5 min starting from 5 min after the injection of $1 \%$ acetic acid ( $10 \mathrm{ml} / \mathrm{kg}$, i.p.). Compared to PDE4B+/+ controls, PDE4B-/ - mice did not exhibit altered nociceptive responses, as evidenced by unchanged latencies of hindpaw licking and tail-flick and number of writhes in the three tests, as revealed by unpaired $t$-tests. 

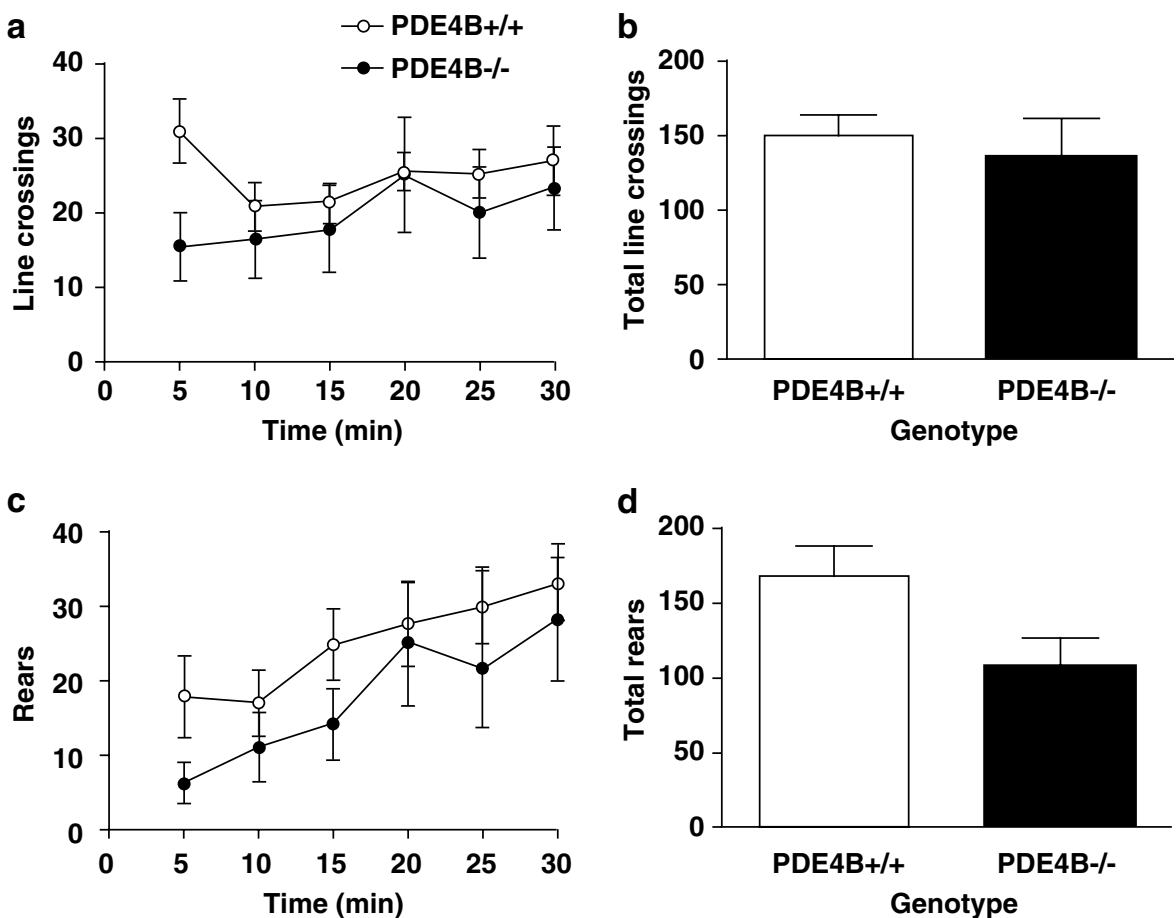

Figure 7 Locomotor activity in the open-field test in PDE4B + / + and PDE4B-/- mice. PDE4B-/ - mice displayed decreases in line crossings during the first 5 min (a) but no change for the 30-min test (b), while rears were not reduced significantly for any 5-min time period (c), they were decreased in the $30-$ min test (d). Line crossings and rears were recorded for every 5 -min period for 30 min. Data shown represent mean \pm SEM of 7-8 mice per group. *P $<0.05$ vs PDE4B $+1+$ mice at the corresponding time point (two-tailed Student's t-test).

other studies have shown that PDE4 inhibitors, including rolipram, result in anxiogenic-like behavior in dogs and mice (Heaslip and Evans, 1995; Imaizumi et al, 1994). The reasons for the inconsistent results may be due, at least partially, to the sedative effect of PDE4 inhibitors (Griebel et al, 1991; Silvestre et al, 1999b) and/or the different contributions of PDE4 subtypes to anxiety regulation. Knockout of individual PDE4 subtypes helps to address these issues.

Mice deficient in PDE4B exhibited behavioral changes in tests sensitive to anxiolytic drugs. PDE4B-/- mice displayed decreases in head-dips and time spent in head-dipping in the holeboard test, an increase in latency before crossing to the light side and decreases in transitions and time spent in the light compartment in the light-dark transition test, and an increase in latency to explore and decreases in exploration and rears in a novel and lighted open-field chamber. All these changes represent typical anxiogenic-like behavior (MacNeil et al, 1997; Pellow, 1986; Suaudeau et al, 2000). Given that PDE4B-I- mice did not display significant changes in locomotor activity, as evidenced by unaltered total line crossings in the open-field test, the behavioral effects of PDE4B deficiency on anxiety tests appeared not to be attributed to sedation. Consistent with the behavioral data, the plasma corticosterone concentrations were increased, but the size of adrenal glands was not changed (data not shown) in PDE4B-/- mice. These are supported by rolipram-induced activation of the hypothalamo-pituitary-adrenal (HPA) axis and increases in plasma corticosterone (Kumari et al, 1997). This pattern of behavior and biochemistry is indicative of an anxiogenic-like effect
(Hascoet and Bourin, 1998; Liebsch et al, 1998; Suaudeau et al, 2000).

Anxiogenic-like behavior of $\mathrm{PDE} 4 \mathrm{~B}-/-$ mice appears to be in agreement with the unique distribution of PDE4B in the mouse brain; this subtype is highly expressed in the hypothalamus and locus coeruleus, relative to the other PDE4 subtypes (Cherry and Davis, 1999). Noradrenergic systems in the hypothalamus, amygdala, and locus coeruleus are involved in the regulation of anxiety. Increases in the release of norepinephrine, which stimulates cAMP formation in the brain (Bettahi et al, 1998; Quesada and Etgen, 2000), produce anxiogenic-like behavior in animals (Tanaka et al, 2000). Although there is no evidence showing a high expression of PDE4B in the mouse amygdala, significantly decreased activity of PDE4 in PDE4B- $/-$ mice indicates that PDE4B most likely is the predominant PDE4 subtype in this region, which is important in anxiety (Wand, 2005). Loss of PDE4B leads to increases in cAMP in these brain regions and results in anxiogenic-like behavior.

PDE4B-I- mice also displayed 'antidepressant-like' behavior, ie reduced immobility in the initial exposure to forced-swim, a behavioral test that is widely used for evaluating antidepressants. Antidepressant treatment typically decreases the immobility duration of animals that are repeatedly exposed to the forced-swim test, even though the baseline of the immobility is increased (Raghavendra et al, 2000; Zhang et al, 2002). This was verified using the same mice 7 weeks later, showing that this was a persistent behavioral change. Interestingly, while acute desipramine or repeated rolipram produced antidepressant-like effects on forced-swim behavior in the wild-type animals, neither treatment significantly altered the immobility duration in 
PDE4B-/- mice, although both tended to produce decreases in immobility. However, 'antidepressant-like' behavior of PDE4B-I- mice was not supported by the TST, which also is a test sensitive to antidepressant drugs and commonly used for assessing antidepressant activity (Cryan et al, 2005). Since PDE4B-/- mice displayed anxiety-like behavior, it is possible that the 'antidepressant-like' effect in the FST resulted from anxiety-related struggling, leading to decreased immobility. This is supported by studies showing that treatment causing anxiogenic-like effects (eg acute pentylenetetrazol or the CRF1 agonist cortagine) results in antidepressant-like behavior in the FST (Cannizzaro et al, 1993; Tezval et al, 2004). Therefore, the 'antidepressant-like' effect of PDE4B-1- mice observed in the FST may be a 'false positive' result. Given that the effects of rolipram and desipramine were attenuated in PDE4B-I- mice, further studies are needed to clarify the effect of PDE4B deficiency on FST behavior and depression-related behaviors in general.

PDE4B-/- mice also displayed a slight, but significant, increase in adult neurogenesis relative to the wild-type controls, as evidenced by increased proliferation of neuronal cells in the subgranular zone of the hippocampal dentate gyrus. Since stress decreases hippocampal neurogenesis, in particular cell proliferation (Warner-Schmidt and Duman, 2006), PDE4B-/- mice might be expected to display a decrease, rather than an increase, in cell proliferation. The inconsistent results may be attributed to the persistent stimulation of CAMP signaling in PDE4B-/mice. It was noted that PDE4 activity in the hippocampus was decreased by $22 \%$, although it was not significantly changed relative to the wild-type controls. While this effect was subtle, probably due to the relatively low levels of PDE4B in the hippocampus (Perez-Torres et al, 2000), longterm decreases in PDE4 activity in PDE4B-/- mice may mimic the effect of PDE4 inhibition by chronic treatment with rolipram, which increases adult hippocampal neurogenesis (Nakagawa et al, 2002). Since rolipram plays its role in neurogenesis via activation of the CAMP/CREB cascade, neurogenesis induced by PDE4B deficiency likely is also mediated by cAMP signaling. Interestingly, chronic administration of the antidepressant fluoxetine, a selective serotonin reuptake inhibitor, not only increases hippocampal neurogenesis (Encinas et al, 2006; Malberg et al, 2000), but also decreases the expression of PDE4B in the brains of mice and rats (Dlaboga et al, 2006; Miro et al, 2002). However, while these findings appear to be consistent with FST behavior and hippocampal neurogenesis observed in PDE4B-Imice, further studies are needed to determine their relationship to antidepressant activity. In addition, these results do not rule out the contributions of other PDE4 subtypes, such as PDE4A and PDE4D, given the consideration of their roles in or association with antidepressant-like behavior (Takahashi et al, 1999; Ye et al, 2000; Zhang et al, 2002).

PDE4B appears not critical for memory processes. While overall inhibition of PDE4 enhances memory performance in animals (Barad et al, 1998; Zhang et al, 2004, 2005), PDE4B $-/-$ mice did not show significant changes in either short- or long-term memory in step-down passive avoidance and Morris water-maze tasks (Table 1 and Figure 5), two tests measuring hippocampus-based memory (Bevilaqua et al, 1997). This is consistent with the limited expression of PDE4B in the hippocampus (Cherry and Davis, 1999). Further studies need to be performed in amygdala- and striatum-based memory models, given that PDE4B is highly expressed in these two regions (Perez-Torres et al, 2000). Similar to the results observed in the memory tests, PDE4B-I- mice did not display any nociceptive responses in the tests sensitive to analgesics (Table 2), although overall inhibition of PDE4 has been reported to produce an analgesic effect (Levy and Goldstein, 1981).

In conclusion, our results indicate that PDE4B is particularly involved in the mediation of behaviors associated with anxiety. Deficiency of PDE4B produces anxiogenic-like behavior in the tests used in the present study. They also showed a slight but significant increase in hippocampal neurogenesis. The behavioral pattern of the anxiogenic-like effect and reduced immobility in the FST observed in PDE4B- $/-$ mice appears not uncommon; it also occurs in BDNF transgenic mice (Govindarajan et al, 2006) and in rats treated acutely with pentylenetetrazol (Cannizzaro et al, 1993) or fluoxetine (Zienowicz et al, 2006). Thus, the present data suggest that PDE4B plays a role in the anxiogenic-like effects of acute rolipram (Heaslip and Evans, 1995; Imaizumi et al, 1994), which also exerts antidepressant activity.

\section{ACKNOWLEDGEMENTS}

This work was supported by research grants from the National Institute of Mental Health (MH51175 and MH40694; to JMO), the Mental Health Research Association (NARSAD; to HTZ), and the National Institute of Child Health and Human Development (HD20788; to MC). We thank Dr Albert S Berrebi and Dr Yongming Jin and $\mathrm{Mr}$ Dennis Cole of West Virginia University Health Sciences Center and Ms Kathleen Horner of Stanford University School of Medicine for their assistance with brain slice preparation and animal perfusion, $\mathrm{Mr}$ Jeffrey B Altemus for his assistance with confocal microscopy, and Dr Leslie R Ballou of Veterans Affairs Medical Center in Memphis, TN for his assistance with the testing of nociceptive effects.

\section{DISCLOSURE/CONFLICT OF INTEREST}

James M O'Donnell is on the Scientific Advisory Board of Fission Pharmaceuticals (unpaid) and has received financial support for his research from Memory Pharmaceuticals, Lundbeck Pharmaceuticals, and Wyeth Pharmaceuticals.

\section{REFERENCES}

Ariga M, Neitzert B, Nakae S, Mottin G, Bertrand C, Pruniaux MP et al (2004). Nonredundant function of phosphodiesterases $4 \mathrm{D}$ and $4 \mathrm{~B}$ in neutrophil recruitment to the site of inflammation. J Immunol 173: 7531-7538.

Baillie GS, Houslay MD (2005). Arrestin times for compartmentalised cAMP signalling and phosphodiesterase-4 enzymes. Curr Opin Cell Biol 17: 129-134.

Ballou LR, Botting RM, Goorha S, Zhang J, Vane JR (2000). Nociception in cyclooxygenase isozyme-deficient mice. Proc Natl Acad Sci USA 97: 10272-10276. 
Barad M, Bourtchouladze R, Winder DG, Golan H, Kandel E (1998). Rolipram, a type IV-specific phosphodiesterase inhibitor, facilitates the establishment of long-lasting long-term potentiation and improves memory. Proc Natl Acad Sci USA 95: 15020-15025.

Beer B, Chasin M, Clody DE, Vogel JR (1972). Cyclic adenosine monophosphate phosphodiesterase in brain: effect on anxiety. Science 176: 428-430.

Bettahi I, Guerrero JM, Reiter RJ, Osuna C (1998). Physiological concentrations of melatonin inhibit the norepinephrine-induced activation of prostaglandin E2 and cyclic AMP production in rat hypothalamus: a mechanism involving inhibition of nitric oxide synthase. J Pineal Res 25: 34-40.

Bevilaqua L, Ardenghi P, Schroder N, Bromberg E, Quevedo J, Schmitz PK et al (1997). Agents that affect cAMP levels or protein kinase A activity modulate memory consolidation when injected into rat hippocampus but not amygdala. Braz J Med Biol Res 30: 967-970.

Biala G, Budzynska B (2006). Effects of acute and chronic nicotine on elevated plus maze in mice: involvement of calcium channels. Life Sci 79: 81-88.

Bohn LM, Xu F, Gainetdinov RR, Caron MG (2000). Potentiated opioid analgesia in norepinephrine transporter knock-out mice. J Neurosci 20: 9040-9045.

Bolger G, Michaeli T, Martins T, St John T, Steiner B, Rodgers L et al (1993). A family of human phosphodiesterases homologous to the dunce learning and memory gene product of Drosophila melanogaster are potential targets for antidepressant drugs. $\mathrm{Mol}$ Cell Biol 13: 6558-6571.

Bolger GB, Rodgers L, Riggs M (1994). Differential CNS expression of alternative mRNA isoforms of the mammalian genes encoding cAMP-specific phosphodiesterases. Gene 149: 237-244.

Bourtchouladze R, Lidge R, Catapano R, Stanley J, Gossweiler S, Romashko D et al (2003). A mouse model of Rubinstein-Taybi syndrome: defective long-term memory is ameliorated by inhibitors of phosphodiesterase 4. Proc Natl Acad Sci USA 100: 10518-10522.

Bradaia A, Berton F, Ferrari S, Luscher C (2005). beta-Arrestin2, interacting with phosphodiesterase 4 , regulates synaptic release probability and presynaptic inhibition by opioids. Proc Natl Acad Sci USA 102: 3034-3039.

Cannizzaro G, Flugy A, Cannizzaro C, Gagliano M, Sabatino M (1993). Effects of desipramine and alprazolam in the forced swim test in rats after long-lasting termination of chronic exposure to picrotoxin and pentylenetetrazol. Eur Neuropsychopharmacol 3: 477-484.

Charney DS, Deutch A (1996). A functional neuroanatomy of anxiety and fear: implications for the pathophysiology and treatment of anxiety disorders. Crit Rev Neurobiol 10: 419-446.

Cherry JA, Davis RL (1999). Cyclic AMP phosphodiesterases are localized in regions of the mouse brain associated with reinforcement, movement, and affect. J Comp Neurol 407: 287-301.

Cherry JA, Thompson BE, Pho V (2001). Diazepam and rolipram differentially inhibit cyclic AMP-specific phosphodiesterases PDE4A1 and PDE4B3 in the mouse. Biochim Biophys Acta 1518: $27-35$.

Cheung YF, Kan Z, Garrett-Engele P, Gall I, Murdoch H, Baillie GS et al (2007). PDE4B5, a novel, super-short, brain-specific cAMP phosphodiesterase-4 variant whose isoform-specifying N-terminal region is identical to that of cAMP phosphodiesterase-4D6 (PDE4D6). J Pharmacol Exp Ther 322: 600-609.

Clapcote SJ, Lipina TV, Millar JK, Mackie S, Christie S, Ogawa F et al (2007). Behavioral phenotypes of disc 1 missense mutations in mice. Neuron 54: 387-402.

Conti M, Richter W, Mehats C, Livera G, Park JY, Jin C (2003). Cyclic AMP-specific PDE4 phosphodiesterases as critical components of cyclic AMP signaling. J Biol Chem 278: 5493-5496.
Cryan JF, Mombereau C, Vassout A (2005). The tail suspension test as a model for assessing antidepressant activity: review of pharmacological and genetic studies in mice. Neurosci Biobehav Rev 29: 571-625.

Dlaboga D, Hajjhussein H, O'Donnell JM (2006). Regulation of phosphodiesterase-4 (PDE4) expression in mouse brain by repeated antidepressant treatment: comparison with rolipram. Brain Res 1096: 104-112.

Dranovsky A, Hen R (2006). Hippocampal neurogenesis: regulation by stress and antidepressants. Biol Psychiatry 59: 1136-1143.

Duman RS, Malberg J, Nakagawa S (2001). Regulation of adult neurogenesis by psychotropic drugs and stress. J Pharmacol Exp Ther 299: 401-407.

El-Ghundi M, Fletcher PJ, Drago J, Sibley DR, O’Dowd BF, George SR (1999). Spatial learning deficit in dopamine $D(1)$ receptor knockout mice. Eur J Pharmacol 383: 95-106.

Encinas JM, Vaahtokari A, Enikolopov G (2006). Fluoxetine targets early progenitor cells in the adult brain. Proc Natl Acad Sci USA 103: $8233-8238$.

Fischmeister R (2006). Is cAMP good or bad? Depends on where it's made. Circ Res 98: 582-584.

Govindarajan A, Rao BS, Nair D, Trinh M, Mawjee N, Tonegawa S et al (2006). Transgenic brain-derived neurotrophic factor expression causes both anxiogenic and antidepressant effects. Proc Natl Acad Sci USA 103: 13208-13213.

Gretarsdottir S, Thorleifsson G, Reynisdottir ST, Manolescu A, Jonsdottir S, Jonsdottir $\mathrm{T}$ et al (2003). The gene encoding phosphodiesterase 4D confers risk of ischemic stroke. Nat Genet 35: $131-138$.

Griebel G, Misslin R, Vogel E, Bourguignon JJ (1991). Behavioral effects of rolipram and structurally related compounds in mice: behavioral sedation of cAMP phosphodiesterase inhibitors. Pharmacol Biochem Behav 39: 321-323.

Hansen G, Jin S, Umetsu DT, Conti M (2000). Absence of muscarinic cholinergic airway responses in mice deficient in the cyclic nucleotide phosphodiesterase PDE4D. Proc Natl Acad Sci USA 97: 6751-6756.

Hascoet M, Bourin M (1998). A new approach to the light/dark test procedure in mice. Pharmacol Biochem Behav 60: 645-653.

Heaslip RJ, Evans DY (1995). Emetic, central nervous system, and pulmonary activities of rolipram in the dog. Eur $J$ Pharmacol 286: 281-290.

Hilakivi LA, Lister RG (1990). Correlations between behavior of mice in Porsolt's swim test and in tests of anxiety, locomotion, and exploration. Behav Neural Biol 53: 153-159.

Houslay MD, Schafer P, Zhang KY (2005). Phosphodiesterase-4 as a therapeutic target. Drug Discov Today 10: 1503-1519.

Huston E, Lumb S, Russell A, Catterall C, Ross A, Steele MR et al (1997). Molecular cloning and transient expression in COS cells of a novel human PDE4B cyclic AMP-specific phosphodiesterase, HSPDE4B3. Biochem J 328: 549-556.

Imaizumi M, Miyazaki S, Onodera K (1994). Effects of a nonxanthine adenosine antagonist, CGS 15943, and a phosphodiesterase inhibitor, Ro 20-1724, in a light/dark test in mice. Methods Find Exp Clin Pharmacol 16: 717-721.

Imanishi T, Sawa A, Ichimaru Y, Miyashiro M, Kato S, Yamamoto $\mathrm{T}$ et al (1997). Ameliorating effects of rolipram on experimentally induced impairments of learning and memory in rodents. Eur J Pharmacol 321: 273-278.

Jin SL, Lan L, Zoudilova M, Conti M (2005a). Specific role of phosphodiesterase $4 \mathrm{~B}$ in lipopolysaccharide-induced signaling in mouse macrophages. J Immunol 175: 1523-1531.

Jin SLC, Latour AM, Conti M (2005b). Generation of PDE4 knockout mice by gene targeting. Methods Mol Biol 307: 191-210.

Jin SLC, Richard FJ, Kuo WP, D’Ercole AJ, Conti M (1999). Impaired growth and fertility of cAMP-specific phosphodiesterase PDE4D-deficient mice. Proc Natl Acad Sci USA 96: 11998-12003. 
Kumar A, Jain NK, Kulkarni SK (2000). Analgesic and antiinflammatory effects of phosphodiesterase inhibitors. Indian J Exp Biol 38: 26-30.

Kumari M, Cover PO, Poyser RH, Buckingham JC (1997). Stimulation of the hypothalamo-pituitary-adrenal axis in the rat by three selective type- 4 phosphodiesterase inhibitors: in vitro and in vivo studies. Br J Pharmacol 121: 459-468.

Lehnart SE, Wehrens XH, Reiken S, Warrier S, Belevych AE, Harvey RD et al (2005). Phosphodiesterase 4D deficiency in the ryanodine-receptor complex promotes heart failure and arrhythmias. Cell 123: 25-35.

Levy RA, Goldstein BD (1981). Analgesia following microinjection of phosphodiesterase inhibitors at brainstem sites. Pharmacol Biochem Behav 15: 501-504.

Liebsch G, Linthorst AC, Neumann ID, Reul JM, Holsboer F, Landgraf R (1998). Behavioral, physiological, and neuroendocrine stress responses and differential sensitivity to diazepam in two Wistar rat lines selectively bred for high- and low-anxietyrelated behavior. Neuropsychopharmacology 19: 381-396.

Lynch MJ, Baillie GS, Mohamed A, Li X, Maisonneuve C, Klussmann E et al (2005). RNA silencing identifies PDE4D5 as the functionally relevant cAMP phosphodiesterase interacting with beta arrestin to control the protein kinase A/AKAP79mediated switching of the beta2-adrenergic receptor to activation of ERK in HEK293B2 cells. J Biol Chem 280: 33178-33189.

MacNeil G, Sela Y, McIntosh J, Zacharko RM (1997). Anxiogenic behavior in the light-dark paradigm following intraventricular administration of cholecystokinin-8S, restraint stress, or uncontrollable footshock in the CD-1 mouse. Pharmacol Biochem Behav 58: 737-746.

Malberg JE, Duman RS (2003). Cell proliferation in adult hippocampus is decreased by inescapable stress: reversal by fluoxetine treatment. Neuropsychopharmacology 28: 1562-1571.

Malberg JE, Eisch AJ, Nestler EJ, Duman RS (2000). Chronic antidepressant treatment increases neurogenesis in adult rat hippocampus. J Neurosci 20: 9104-9110.

Maurice T, Privat A (1997). SA4503, a novel cognitive enhancer with $\sigma_{1}$ receptor agonist properties, facilitates NMDA receptordependent learning in mice. Eur J Pharmacol 328: 9-18.

Millar JK, Pickard BS, Mackie S, James R, Christie S, Buchanan SR et al (2005). DISC1 and PDE4B are interacting genetic factors in schizophrenia that regulate cAMP signaling. Science 310: 1187-1191.

Miro X, Perez-Torres S, Artigas F, Puigdomenech P, Palacios JM, Mengod G (2002). Regulation of cAMP phosphodiesterase mRNAs expression in rat brain by acute and chronic fluoxetine treatment. An in situ hybridization study. Neuropharmacology 43: $1148-1157$.

Moreira EG, Nascimento N, Rogero JR, Vassilieff VS (2000). Gabaergic-benzodiazepine system is involved in the crotoxininduced anxiogenic effect. Pharmacol Biochem Behav 65: 7-13.

Nakagawa S, Kim JE, Lee R, Malberg JE, Chen J, Steffen C et al (2002). Regulation of neurogenesis in adult mouse hippocampus by cAMP and the cAMP response element-binding protein. J Neurosci 22: 3673-3682.

O'Donnell JM, Zhang HT (2004). Antidepressant effects of inhibitors of cAMP phosphodiesterase (PDE4). Trends Pharmacol Sci 25: $158-163$.

Pellow S (1986). Anxiolytic and anxiogenic drug effects in a novel test of anxiety: are exploratory models of anxiety in rodents valid? Methods Find Exp Clin Pharmacol 8: 557-565.

Perez-Torres S, Miro X, Palacios JM, Cortes R, Puigdomenech P, Mengod G (2000). Phosphodiesterase type 4 isozymes expression in human brain examined by in situ hybridization histochemistry and $[3 \mathrm{H}]$ rolipram binding autoradiography. Comparison with monkey and rat brain. J Chem Neuroanat 20: 349-374.

Polesskaya OO, Smith RF, Fryxell KJ (2007). Chronic nicotine doses down-regulate PDE4 isoforms that are targets of antidepressants in adolescent female rats. Biol Psychiatry 61 56-64.

Quesada A, Etgen AM (2000). Tyrosine kinase effects on adrenoceptor-stimulated cyclic AMP accumulation in preoptic area and hypothalamus of female rats: modulation by estradiol. Brain Res 861: 117-125.

Raghavendra V, Kaur G, Kulkarni SK (2000). Antidepressant action of melatonin in chronic forced swimming-induced behavioral despair in mice, role of peripheral benzodiazepine receptor modulation. Eur Neuropsychopharmacol 10: 473-481.

Rich TC, Xin W, Mehats C, Hassell KA, Piggott LA, Le X et al (2007). Cellular mechanisms underlying prostaglandin-induced transient cAMP signals near the plasma membrane of HEK-293 cells. Am J Physiol Cell Physiol 292: C319-C331.

Richter W, Jin SL, Conti M (2005). Splice variants of the cyclic nucleotide phosphodiesterase PDE4D are differentially expressed and regulated in rat tissue. Biochem J 388: 803-811.

Santarelli L, Saxe M, Gross C, Surget A, Battaglia F, Dulawa S et al (2003). Requirement of hippocampal neurogenesis for the behavioral effects of antidepressants. Science 301: 805-809.

Semba J, Mataki C, Yamada S, Nankai M, Toru M (1998). Antidepressant like effects of chronic nicotine on learned helplessness paradigm in rats. Biol Psychiatry 43: 389-391.

Shepherd M, McSorley T, Olsen AE, Johnston LA, Thomson NC, Baillie GS et al (2003). Molecular cloning and subcellular distribution of the novel PDE4B4 cAMP-specific phosphodiesterase isoform. Biochem J 370: 429-438.

Silvestre JS, Fernandez AG, Palacios JM (1999a). Effects of rolipram on the elevated plus-maze test in rats: a preliminary study. J Psychopharmacol 13: 274-277.

Silvestre JS, Fernandez AG, Palacios JM (1999b). Preliminary evidence for an involvement of the cholinergic system in the sedative effects of rolipram in rats. Pharmacol Biochem Behav 64: $1-5$.

Siuciak JA, Chapin DS, McCarthy SA, Martin AN (2007). Antipsychotic profile of rolipram: efficacy in rats and reduced sensitivity in mice deficient in the phosphodiesterase-4B (PDE4B) enzyme. Psychopharmacology (Berl) 192: 415-424.

Soares JC, Mann JJ (1997). The functional neuroanatomy of mood disorders. J Psychiatr Res 31: 393-432.

Suaudeau C, Rinaldi D, Lepicard E, Venault P, Crusio WE, Costentin J et al (2000). Divergent levels of anxiety in mice selected for differences in sensitivity to a convulsant agent. Physiol Behav 71: 517-523.

Takahashi M, Terwilliger R, Lane C, Mezes PS, Conti M, Duman RS (1999). Chronic antidepressant administration increases the expression of cAMP-specific phosphodiesterase $4 \mathrm{~A}$ and $4 \mathrm{~B}$ isoforms. J Neurosci 19: 610-618.

Tanaka M, Yoshida M, Emoto H, Ishii H (2000). Noradrenaline systems in the hypothalamus, amygdala and locus coeruleus are involved in the provocation of anxiety: basic studies. Eur $J$ Pharmacol 405: 397-406.

Terrin A, Di Benedetto G, Pertegato V, Cheung YF, Baillie G, Lynch MJ et al (2006). PGE(1) stimulation of HEK293 cells generates multiple contiguous domains with different [cAMP]: role of compartmentalized phosphodiesterases. J Cell Biol 175: 441-451.

Tezval H, Jahn O, Todorovic C, Sasse A, Eckart K, Spiess J (2004). Cortagine, a specific agonist of corticotropinreleasing factor receptor subtype 1 , is anxiogenic and antidepressive in the mouse model. Proc Natl Acad Sci USA 101: 9468-9473.

Wand G (2005). The anxious amygdala: CREB signaling and predisposition to anxiety and alcoholism. J Clin Invest 115: 2697-2699.

Warner-Schmidt JL, Duman RS (2006). Hippocampal neurogenesis: opposing effects of stress and antidepressant treatment. Hippocampus 16: 239-249. 
Webster HH, Flores G, Marcotte ER, Cecyre D, Quirion R, Srivastava LK (2000). Olfactory bulbectomy alters NMDA receptor levels in the rat prefrontal cortex. Synapse 37: 159-162.

Ye Y, Jackson K, O'Donnell JM (2000). Effects of repeated antidepressant treatment of type $4 \mathrm{~A}$ phosphodiesterase (PDE4A) in rat brain. J Neurochem 74: 1257-1262.

Zee RY, Brophy VH, Cheng S, Hegener HH, Erlich HA, Ridker PM (2006). Polymorphisms of the phosphodiesterase 4D, cAMPspecific (PDE4D) gene and risk of ischemic stroke: a prospective, nested case-control evaluation. Stroke 37: 2012-2017.

Zhang HT, O'Donnell JM (2007). PDE4 as a target mediating antidepressant and cognitive effects on behavior. In: Beavo JA, Francis SH, Houslay MD (eds). Phosphodiesterases in Health and Disease. CRC Press: London, UK. pp 539-558.

Zhang HT, Crissman AM, Dorairaj NR, Chandler LJ, O'Donnell JM (2000). Inhibition of cyclic AMP phosphodiesterase (PDE4) reverses memory deficits associated with NMDA receptor antagonism. Neuropsychopharmacology 23: 198-204.

Zhang HT, Huang Y, Jin SLC, Frith SA, Suvarna N, Conti M et al (2002). Antidepressant-like profile and reduced sensitivity to rolipram in mice deficient in the PDE4D phosphodiesterase enzyme. Neuropsychopharmacology 27: 587-595.

Zhang HT, Huang Y, Suvarna NU, Deng C, Crissman AM, Hopper $\mathrm{AT}$ et al (2005). Effects of the novel PDE4 inhibitors MEM1018 and MEM1091 on memory in the radial-arm maze and inhibitory avoidance tests in rats. Psychopharmacology (Berl) 179: 613-619.

Zhang HT, Zhao Y, Huang Y, Deng C, Hopper AT, De Vivo M et al (2006). Antidepressant-like effects of PDE4 inhibitors mediated by the high-affinity rolipram binding state (HARBS) of the phosphodiesterase-4 enzyme (PDE4) in rats. Psychopharmacology (Berl) 186: 209-217.

Zhang HT, Zhao Y, Huang Y, Dorairaj NR, Chandler LJ, O'Donnell JM (2004). Inhibition of the phosphodiesterase 4 (PDE4) enzyme reverses memory deficits produced by infusion of the MEK inhibitor U0126 into the CA1 subregion of the rat hippocampus. Neuropsychopharmacology 29: 1432-1439.

Zienowicz M, Wislowska-Stanek A, Lehner M, Taracha E, Maciejak $\mathrm{P}$, Sobolewska A et al (2006). Fluoxetine-induced anxiety and nervousness. Pharmacol Rep 58: 115-119. 